\title{
Use of approximate methods to determine minimum reflux ratio in distillation process
}

\author{
Beltrán-Prieto Juan Carlos ${ }^{1, *}$, Kolomaznik Karel $^{1}$ \\ ${ }^{1}$ Faculty of Applied Informatics, Tomas Bata University in Zlín, nám. T. G. Masaryka 5555, 76001 Zlín, Czech Republic
}

\begin{abstract}
The study of multicomponent distillation process require the solution of system of equations developed after mass balance, equilibrium, enthalpy balance, molar fraction analysis were classic methods developed after Lewis-Matheson and Thiele-Geddes studies used in conventional column studies . In many cases, the design of the multi-stage equipment requires a rigorous determination of parameters (i.e. temperature, pressure, flows and compositions of streams. Given the high no linearity of the equations it is necessary to solve the system by using iterative procedures, where the methods differ in the selection of the set of independent variables. In the present paper we aim to use approximate methods to determine the minimum reflux ratio, amount of theoretical zones and feed location in the process of distillation.
\end{abstract}

\section{Introduction}

In the design of distillation columns is very useful to know the number of plates required to achieve the separation when the product is not removed from the column (total reflux) and the minimum reflux ratio that can be used to achieve the expected separation. Even the existence of rigorous methods to determine and achieve the separation of multicomponent systems, approximate methods such as Fenske-Underwood-Gilliland, Kremser, Edmister and its variations keep being utilized for several purposes [1], such as preliminary design, parametric studies for optimum design, process simplification to determine optimum separation sequence, information about operating pressure, equilibrium stages or reflux ratio [2]. These methods can be applied using hand calculations when the physical properties are independent of composition, however, as often the calculations involve iterative procedures, it is advisable the use of computational systems [3].

The separation of compounds by distillation occurs when the concentration of fluid phases are different from each other at equilibrium [3]. Generally, the gas phase contains the more volatile component. Mathematical analysis of distillation and absorption process consists of material and energy balances and phase equilibrium relations. Two type of equipment are generally used, tray or packed, stagewise or continuous. Selection of the system produces stepwise changes in concentration or gradual variation concentration. A plate-type of distillation column where a fluid flows down the column is an example of stagewise system. Fluid streams are mixed until thermodynamic equilibrium is reached, then separation is achieved and each phase passes countercurrently to the next stage [4]. Distillation is a separation process that is under optimization particularly in terms of energy consumption as is the most significant energy-consuming process, which can be achieved by appropriate sequencing of the columns [5]. One of the main challenges is that multicomponent systems exhibit transport characteristics completely different from classical and simple binary systems [6].

In the present article, we analyze the case of multicomponent distillation in which a feed of $100 \mathrm{~mol} / \mathrm{h}$ are added to a fractionating tower at the boiling point and $405.3 \mathrm{kPa}$ pressure. The system consists of a mixture of $C_{4} H_{10} \quad\left(x_{A}=0.37\right), C_{5} H_{12} \quad\left(x_{B}=0.28\right), \quad C_{6} H_{12}$ $\left(x_{C}=0.18\right), C_{7} H_{14}\left(x_{D}=0.17\right)$. We aim to determine the characterization of light and heavy phase, component distribution, tower temperature, particularly at top and bottom. Accordingly, we approach the use of approximate methods to determine the minimum reflux ratio, amount of theoretical zones and feed location.

\section{Description of the system}

We start the analysis considering that $C_{5} H_{12}$ will be mainly recovered in the distillate $(95 \%)$ and $C_{6} H_{12}$ will remain in the bottoms (95\%). It is necessary to perform a mass balance for each component, $(F=D+W)$, where $\mathrm{F}$ is the feed, $\mathrm{D}$ is the distillate and $\mathrm{W}$ the bottoms fraction.

For $\mathrm{C}_{5} \mathrm{H}_{12}$ we obtain

$$
\begin{gathered}
x_{B_{-} F} \cdot F=0.28(100)=28 \\
x_{B_{-} F} \cdot F=y_{B_{-} D} \cdot D+x_{B_{-} W} \cdot W
\end{gathered}
$$

Taking into consideration that $95 \%$ of $C_{5} H_{12}$ is distilled we determine $y_{B_{-} D} \cdot D=0.95(28)=26.6$. Therefore, $x_{B_{-} W} \cdot W=0.05(28)=1.25$.

For $C_{6} H_{14}$ we would obtain the next values:

\footnotetext{
*Corresponding author: prieto@fai.utb.cz
} 


$$
\begin{aligned}
& x_{C_{-} F} \cdot F=0.18(100)=18 \\
& x_{C_{-} F} \cdot F=y_{C_{-} D} \cdot D+x_{C_{-} W} \cdot W \\
& y_{C_{-} D} \cdot D=0.05(18)=0.9 \\
& x_{C_{-} W} \cdot W=0.95(18)=17.1
\end{aligned}
$$

We assume that there is no $\mathrm{C}_{7} \mathrm{H}_{14}$ in the distillate and no $C_{4} H_{10}$ in the bottom. As a result, we can obtain the flow of $C_{4} H_{10}$ i and $C_{7} H_{16}$ in distillate and bottoms respectively.

$$
\begin{aligned}
& y_{A_{-} D} \cdot D=0.4(100)=40 \\
& x_{D_{-} W} \cdot W=0.15(100)=15
\end{aligned}
$$

Therefore, we obtain the next table that describes the composition of distillate and bottoms.

Table 1. Characterization of distillate and bottoms.

\begin{tabular}{|c|c|c|c|c|c|c|}
\hline \multirow{2}{*}{ component } & \multicolumn{2}{|c|}{ Feed } & \multicolumn{2}{c|}{ Distillate, D } & \multicolumn{2}{c|}{ Bottoms, W } \\
\cline { 2 - 7 } & $\begin{array}{c}\boldsymbol{x}_{\boldsymbol{F}} \cdot \boldsymbol{F} \\
(\mathrm{mol} / \mathrm{h})\end{array}$ & $\boldsymbol{x}_{-} \boldsymbol{F}$ & $\begin{array}{c}\boldsymbol{y}_{\boldsymbol{D}} \cdot \boldsymbol{D} \\
(\mathrm{mol} / \mathrm{h})\end{array}$ & $\boldsymbol{y}_{-\boldsymbol{D}}=\boldsymbol{x}_{-} \boldsymbol{D}$ & $\begin{array}{c}\boldsymbol{x}_{-\boldsymbol{W}} \cdot \boldsymbol{W} \\
(\mathrm{mol} / \mathrm{h})\end{array}$ & $\boldsymbol{x}_{-\boldsymbol{W}}$ \\
\hline$C_{4} H_{10}$ & 37 & 0.37 & 37 & 0.5736 & 0 & 0 \\
\hline$C_{5} H_{12}$ & 28 & 0.28 & 26.6 & 0.4124 & 1.4 & 0.04 \\
\hline$C_{6} H_{14}$ & 18 & 0.18 & 0.9 & 0.014 & 17.1 & 0.481 \\
\hline$C_{7} H_{16}$ & 17 & 0.17 & 0 & 0 & 17 & 0.478 \\
\hline total & 100 & 1 & 64.5 & 1 & 35.5 & 1 \\
\hline
\end{tabular}

In order to determine the dew point of the distillate (top temperature) we use an iterative method with an initial guess of $67^{\circ} \mathrm{C}$. Then we proceed to determine $k_{i}$, $\alpha_{i}$, and $K_{C}$ values for each component. The equilibrium $K$ values for light hydrocarbons $\left(\mathrm{C}_{4} \mathrm{H}_{10}\right.$ to $\left.\mathrm{C}_{10} \mathrm{H}_{22}\right)$ at 405.3 $\mathrm{kPa}$ have been determined semi-empirically and therefore can be evaluated. The parameters $\delta, \beta$ and $\gamma$ correspond to constant values provided in Table 2 [7].

$$
\begin{gathered}
k=e^{-\delta / T^{2}+\beta-\gamma} \\
\alpha_{i}=\frac{k_{i}}{k_{r e f}} \\
K_{C}=\sum\left(\frac{y_{i}}{\alpha_{i}}\right)
\end{gathered}
$$

Then, a new value of temperature is obtained using the value of $K_{C}$ determined previously, and is compared to the assumed temperature value. If both values are equal, the dew point is determined at this value, if not, the temperature is used to find new set of $k_{i}, \alpha_{i}$, and $K_{C}$ values and a new value of temperature is calculated with these parameters, until both values match each other. Then, the composition in the liquid is calculated using equation

\begin{tabular}{|c|c|c|c|c|c|}
\hline component & $\mathrm{T}\left({ }^{\circ} \mathrm{C}\right)$ & $k$ & $\alpha$ & $y_{-D} / \alpha$ & $K_{C}$ \\
\hline $\mathrm{C}_{4} \mathrm{H}_{10}$ & \multirow{4}{*}{65.85} & 1.765 & 6.27 & 0.0913 & \multirow{4}{*}{0.279} \\
\hline $\mathrm{C}_{5} \mathrm{H}_{12}$ & & 0.665 & 2.360 & 0.1742 & \\
\hline $\mathrm{C}_{6} \mathrm{H}_{14}$ & & 0.281 & 1.000 & 0.0139 & \\
\hline$C_{7} H_{16}$ & & 0.118 & 0.422 & 0 & \\
\hline $\mathrm{C}_{4} \mathrm{H}_{10}$ & \multirow{4}{*}{65.64} & 1.758 & 6.289 & 0.0912 & \multirow{4}{*}{0.279} \\
\hline$C_{5} H_{12}$ & & 0.662 & 2.368 & 0.1741 & \\
\hline $\mathrm{C}_{6} \mathrm{H}_{14}$ & & 0.279 & 1.000 & 0.0139 & \\
\hline$C_{7} H_{16}$ & & 0.118 & 0.422 & 0.000 & \\
\hline$C_{4} H_{10}$ & \multirow{4}{*}{65.6} & 1.757 & 6.29 & 0.091 & \multirow{4}{*}{0.279} \\
\hline $\mathrm{C}_{5} \mathrm{H}_{12}$ & & 0.661 & 2.36 & 0.174 & \\
\hline $\mathrm{C}_{6} \mathrm{H}_{14}$ & & 0.279 & 1.000 & 0.0139 & \\
\hline$C_{7} H_{16}$ & & 0.118 & 0.422 & 0 & \\
\hline
\end{tabular}

$$
x_{i}=\frac{y_{i}}{\alpha_{i} \sum\left(y_{i} / \alpha_{i}\right)}
$$

Table 2. Constant values to be used in the present system [7].

\begin{tabular}{|c|c|c|c|}
\hline component & $\boldsymbol{\delta}$ & $\boldsymbol{\beta}$ & $\boldsymbol{\gamma}$ \\
\hline$C_{4} H_{10}$ & 1280557 & 7.94986 & 0.96455 \\
\hline$C_{5} H_{12}$ & 1524891 & 7.33129 & 0.89143 \\
\hline$C_{6} H_{14}$ & 1778901 & 6.96783 & 0.84634 \\
\hline$C_{7} H_{16}$ & 2013803 & 6.52914 & 0.79543 \\
\hline
\end{tabular}

Table 3 Composition of distillate and determination of $k, \alpha$ and $y_{D} / \alpha$ values.

\begin{tabular}{|c|c|c|c|c|}
\hline component & $\boldsymbol{y}_{-} \boldsymbol{D}$ & $\boldsymbol{k}$ & $\boldsymbol{\alpha}$ & $\boldsymbol{y}_{-} \boldsymbol{D} / \boldsymbol{\alpha}$ \\
\hline$C_{4} H_{10}$ & 0.5736 & 1.8072 & 6.223 & 0.0928 \\
\hline$C_{5} H_{12}$ & 0.4124 & 0.684 & 2.355 & 0.175 \\
\hline$C_{6} H_{14}$ & 0.01395 & 0.29 & 1 & 0.0139 \\
\hline$C_{7} H_{16}$ & 0 & 0.1232 & 0.424 & 0 \\
\hline
\end{tabular}

Table 4. Example of subsequent iteration procedure.

Table 5. Liquid Composition at dew point.

\begin{tabular}{|c|c|c|}
\hline $\mathbf{T}\left({ }^{\circ} \mathbf{C}\right)$ & component & $\boldsymbol{y}_{\boldsymbol{i}} /\left[\boldsymbol{\alpha}_{\boldsymbol{i}} \sum\left(\boldsymbol{y}_{\boldsymbol{i}} / \boldsymbol{\alpha}_{\boldsymbol{i}}\right)\right]$ \\
\hline \multirow{4}{*}{65.6} & $C_{4} H_{10}$ & 0.3265 \\
\cline { 2 - 3 } & $C_{5} H_{12}$ & 0.6235 \\
\cline { 2 - 3 } & $C_{6} H_{14}$ & 0.0499 \\
\cline { 2 - 3 } & $C_{7} H_{16}$ & 0 \\
\hline
\end{tabular}

Table 6. Composition of bottoms and determination of $k, \alpha$ and $\mathrm{x}_{-} \mathrm{W} \cdot \alpha$ values.

\begin{tabular}{|c|c|c|c|c|c|}
\hline component & $\boldsymbol{x}_{\_} \boldsymbol{w}$ & $\boldsymbol{k}$ & $\boldsymbol{\alpha}$ & $\boldsymbol{x}_{\_} \boldsymbol{W} * \boldsymbol{\alpha}$ & $\boldsymbol{K}_{\boldsymbol{C}}$ \\
\hline$C_{4} H_{10}$ & 0.00000 & 5.01 & 4.18 & 0.00 & \\
\cline { 1 - 5 }$C_{5} H_{12}$ & 0.0394 & 2.30 & 1.92 & 0.075 & \multirow{2}{*}{1.2459} \\
\cline { 1 - 5 }$C_{6} H_{14}$ & 0.4816 & 1.19 & 1.00 & 0.4816 & \\
\cline { 1 - 5 }$C_{7} H_{16}$ & 0.4788 & 0.61 & 0.51 & 0.245 & \\
\hline
\end{tabular}


Table 7. Example of subsequent iteration procedure.

\begin{tabular}{|c|c|c|c|c|c|}
\hline component & $\mathrm{T}\left({ }^{\circ} \mathrm{C}\right)$ & $\boldsymbol{k}$ & $\alpha$ & $x_{-W} * \alpha$ & $\boldsymbol{K}_{C}$ \\
\hline $\mathrm{C}_{4} \mathrm{H}_{10}$ & \multirow{4}{*}{135.4} & 5.156 & 4.130 & 0.000 & \multirow{4}{*}{1.2446} \\
\hline$C_{5} H_{12}$ & & 2.383 & 1.913 & 0.075 & \\
\hline $\mathrm{C}_{6} \mathrm{H}_{14}$ & & 1.24 & 1.000 & 0.481 & \\
\hline $\mathrm{C}_{7} \mathrm{H}_{16}$ & & 0.648 & 0.514 & 0.246 & \\
\hline $\mathrm{C}_{4} \mathrm{H}_{10}$ & \multirow{4}{*}{135.36} & 5.152 & 4.138 & 0.000 & \multirow{4}{*}{1.244} \\
\hline$C_{5} H_{12}$ & & 2.381 & 1.913 & 0.075 & \\
\hline $\mathrm{C}_{6} \mathrm{H}_{14}$ & & 1.246 & 1.000 & 0.481 & \\
\hline $\mathrm{C}_{7} \mathrm{H}_{16}$ & & 0.641 & 0.514 & 0.246 & \\
\hline
\end{tabular}

Table 8. Liquid Composition at bottom of tower.

\begin{tabular}{|c|c|c|}
\hline $\mathbf{T}\left({ }^{\circ} \mathbf{C}\right)$ & component & $\boldsymbol{x}_{-} \boldsymbol{W} * \boldsymbol{\alpha} /\left[\sum\left(\boldsymbol{x}_{-} \boldsymbol{w} * \boldsymbol{\alpha}\right)\right]$ \\
\hline \multirow{4}{*}{135.36} & $C_{4} H_{10}$ & 0 \\
\cline { 2 - 3 } & $C_{5} H_{12}$ & 0.094 \\
\cline { 2 - 3 } & $C_{6} H_{14}$ & 0.60 \\
\cline { 2 - 3 } & $C_{7} H_{16}$ & 0.307 \\
\hline
\end{tabular}

In order to determine the minimum theoretical stages $\left(N_{M}\right)$ required for total reflux we refer to Fenske equation as expressed next [8]:

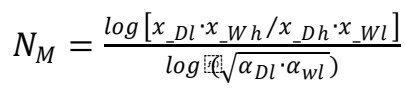

$x_{D l}$ refers to the mole fraction in the light phase in distillate, $x_{-W l}$ is the mole fraction in the bottom, $x_{-} D h$ is the mole fraction of heavy phase in distillate and $x_{-W h}$ the fraction mol of heavy phase in the bottom.

$$
N_{M}=\frac{\log [0.4124 \cdot 0.4816 / 0.01395 \cdot 0.03943]}{\log ((\sqrt{2.369 \cdot 1.914})}=7.8
$$

Table 9. Component distribution. Determination of traces.

\begin{tabular}{|c|c|c|c|}
\hline component & $\boldsymbol{\alpha}_{\boldsymbol{D}}$ & $\boldsymbol{\alpha}_{\boldsymbol{W}}$ & $\sqrt{\boldsymbol{\alpha}_{\boldsymbol{W}} \boldsymbol{\alpha}_{\boldsymbol{D}}}$ \\
\hline$C_{4} H_{10}$ & 6.292 & 4.139 & 5.103 \\
\hline$C_{5} H_{12}$ & 2.369 & 1.914 & 2.129 \\
\hline$C_{6} H_{14}$ & 1.000 & 1.000 & 1 \\
\hline$C_{7} H_{16}$ & 0.422 & 0.514 & 0.466 \\
\hline
\end{tabular}

For $C_{4} H_{10}$

$$
\begin{gathered}
\frac{D \cdot x_{C_{4} H_{10} D}}{W \cdot x_{C_{4} H} H_{10} W}=\left(\sqrt{\alpha_{W} \alpha_{D}}\right)^{N_{M}} \frac{D \cdot x_{D h}}{W \cdot x_{W h}} \\
\frac{D \cdot x_{C_{4} H_{10} D}}{W \cdot x_{C_{4} H}{ }_{10} W}=(5.103)^{7.79} \frac{64.75 \cdot 0.01395}{35.5 \cdot 0.481} \\
\frac{D \cdot x_{C_{4} H_{10} D}}{W \cdot x_{C_{4} H_{10} W}}=17318.1
\end{gathered}
$$

The overall balance on $C_{4} H_{10}$ leads to $x_{C_{4} H_{10} F} \cdot F=$ $x_{C_{4} H_{10} D} \cdot D+x_{C_{4} H_{10} W} \cdot W$. Thus, the next equations are obtained:

$$
\begin{gathered}
x_{C_{4} H_{10} F} \cdot F=17318 \cdot W \cdot x_{C_{4} H_{10} W}+x_{C_{4} H_{10} W} \cdot W \\
37=17318 \cdot W \cdot x_{C_{4} H_{10} W} \\
W \cdot x_{C_{4} H_{10} W}=0.0021 \mathrm{~mol} \\
x_{C_{4} H_{10} D} \cdot D=17318 \cdot W \cdot x_{C_{4} H_{10} W} \\
x_{C_{4} H_{10} D} \cdot D=36.99
\end{gathered}
$$

For $\mathrm{C}_{7} \mathrm{H}_{14}$ :

$$
\begin{aligned}
\frac{D \cdot x_{C_{7} H_{14} D}}{W \cdot x_{C_{7} H_{14} W}} & =\left(\sqrt{\alpha_{W} \alpha_{D}}\right)^{N_{M}} \frac{D \cdot x_{D h}}{W \cdot x_{W h}}= \\
(0.463)^{7.8} \frac{64.5 \cdot 0.0139}{35.5 \cdot 0.478} & =0.000137
\end{aligned}
$$

The overall balance on $C_{7} H_{14}$ leads to $x_{C_{7} H_{14} F} \cdot F=$ $\mathrm{x}_{\mathrm{C}_{7} \mathrm{H}_{14} \mathrm{D}} \cdot \mathrm{D}+\mathrm{x}_{\mathrm{C}_{7} \mathrm{H}_{14} \mathrm{~W}} \cdot \mathrm{W}$

$$
\begin{aligned}
& x_{C_{7} H_{14} F} \cdot F=D \cdot x_{C_{7} H_{14} D}+x_{C_{7} H_{14} W} \cdot W \\
& 17=1.00018 \cdot W \cdot x_{C_{7} H_{14} W} \\
& W \cdot x_{C_{7} H_{14} W}=16.997 \mathrm{~mol} \\
& x_{C_{7} H_{14} D} \cdot D=0.000036 \cdot W \cdot x_{C_{7} H_{14} W} \\
& x_{C_{7} H_{14} D} \cdot D=0.0023
\end{aligned}
$$

Therefore, the new composition is as described in Table 10

Table 10. Characterization of distillate and bottoms.

\begin{tabular}{|c|l|c|c|c|}
\hline & \multicolumn{2}{|l|}{ Distillate, D } & \multicolumn{2}{l|}{ Bottoms, W } \\
\hline compound & $\boldsymbol{y}_{-} \boldsymbol{D}=\boldsymbol{x}_{-} \boldsymbol{D}$ & $\begin{array}{c}\boldsymbol{x}_{\mathbf{D}} \cdot \boldsymbol{D} \\
(\mathrm{mol} / \mathrm{h})\end{array}$ & $\boldsymbol{x}_{-} \boldsymbol{W}$ & $\begin{array}{c}\boldsymbol{x}_{\_} \boldsymbol{W} \cdot \boldsymbol{W} \\
(\mathrm{mol} / \mathbf{h})\end{array}$ \\
\hline$C_{4} H_{10}$ & 0.5736 & 36.9979 & 0.0001 & 0.0021 \\
\hline$C_{5} H_{12}$ & 0.4124 & 26.6 & 0.0394 & 1.400 \\
\hline$C_{6} H_{14}$ & 0.014 & 0.9 & 0.4817 & 17.100 \\
\hline$C_{7} H_{16}$ & 0.000036 & 0.0023 & 0.478 & 16.997 \\
\hline Total & 1.0000 & 64.50 & 1.000 & 35.500 \\
\hline
\end{tabular}

This shows that the traces are $x_{C_{7} H_{14} D}=3.6 \times 10^{-5}$ and $x_{C_{7} H_{14} W}=1 \times 10^{-4}$

The Underwood method is used to determine the minimum reflux ratio. In this method it is required to consider all the components under the conditions of minimum reflux [9]. The equations used to calculate the minimum reflux ratio are described in (29) and (30) where $\mathrm{q}=1$ when feed is at boiling point

$$
\begin{gathered}
1-q=\sum \frac{\alpha_{i} \cdot x_{-} F}{\alpha_{i}-\theta}, \\
R_{m}+1=\sum \frac{\alpha_{i} \cdot x_{-} D}{\alpha_{i}-\theta} \\
T=\left(T_{\text {top }}+T_{\text {bottom }}\right) / 2=\frac{65.6+135.36}{2}=100.48
\end{gathered}
$$

At this temperature, values of $k$ and $\alpha$ are determined, as shown inTable 11. 
Table 11. Determination of $\alpha$ and $x_{-} D$ values required for Underwood method.

\begin{tabular}{|c|c|c|c|c|}
\hline component & $\boldsymbol{x}_{-\boldsymbol{F}}$ & $\boldsymbol{k}\left(\mathbf{9 8 . 8}{ }^{\circ} \mathbf{C}\right)$ & $\boldsymbol{\alpha}$ & $\boldsymbol{x}_{-} \boldsymbol{D}$ \\
\hline$C_{4} H_{10}$ & 0.370 & 3.243 & 4.956 & 0.574 \\
\hline$C_{5} H_{12}$ & 0.280 & 1.373 & 2.098 & 0.412 \\
\hline$C_{6} H_{14}$ & 0.180 & 0.654 & 1.000 & 0.014 \\
\hline$C_{7} H_{16}$ & 0.170 & 0.309 & 0.472 & 0.000036 \\
\hline
\end{tabular}

$$
\begin{gathered}
1-1=\frac{4.956 \cdot 0.37}{4.956-\theta}+\frac{2.098 \cdot 0.28}{2.098-\theta}+\frac{1 \cdot 0.18}{1-\theta}+\frac{0.472 \cdot 0.17}{0.472-\theta} \\
0=\frac{1.8337}{4.956-\theta}+\frac{0.58744}{2.098-\theta}+\frac{0.18}{1-\theta}+\frac{0.08024}{0.472-\theta}
\end{gathered}
$$

Using an algorithm developed to solve the previous equation using implicit method, the values of $\theta$ that satisfy the equation are 0.5398 and 1.1789 . However, the real value has to be between $\alpha_{C_{5} H_{12}}$ and $\alpha_{C_{6} H_{14}}$, therefore, the value corresponds to $\theta=1.1789$. As a result, the minimum reflux ratio is given by

$$
\begin{gathered}
R_{m}=\frac{4.956 \cdot 0.574}{4.956-1.1789}+\frac{2.098 \cdot 0.412}{2.098-1.1789}+\frac{1 \cdot 0.014}{1-1.1789}+ \\
\frac{0.472 \cdot 0.000036}{0.472-1.1789}-1 \\
R_{m}=0.6153
\end{gathered}
$$

We then proceed to determine the number of theoretical stages at different operational reflux ratio, when $R=1.5 R_{m}=1.5 * 0.6153=0.923$. Using the ErbarMaddox correlation, we have

$$
\begin{gathered}
\frac{R}{R+1}=\frac{0.923}{1+0.923}=0.4799 \\
\frac{R_{m}}{R_{m}+1}=\frac{0.6153}{1+0.6153}=0.381
\end{gathered}
$$

Following, it is possible to estimate the requirements in terms of number of ideal stages required using empirical correlation methods like Erbar and Maddox, which describes the ratio of stages required to the total reflux, as a function of the reflux ratio, considering the minimum reflux ratio as a parameter. Hence, $N_{M} / N=$ 0.6. Following, $\quad N=N_{M} / 0.6=7.8 / 0.6=$ 13 theoretical stages.

Feed point location can be estimated considering Kirkbride method

$$
\begin{gathered}
\log \frac{N_{e}}{N_{s}}=0.206 \log \left[\left(\frac{x_{H F}}{x_{L F}}\right) \frac{W}{D}\left(\frac{x_{L W}}{x_{H D}}\right)^{2}\right] \\
\log \frac{N_{e}}{N_{s}}=0.206 \log \left[\left(\frac{0.18}{0.28}\right) \frac{35.5}{64.5}\left(\frac{0.0394}{0.014}\right)^{2}\right] \\
\log \frac{N_{e}}{N_{s}}=0.092189 \\
\frac{N_{e}}{N_{s}}=1.23
\end{gathered}
$$

$N_{e}=1.23 \cdot N_{s} ; N=N_{e}+N_{s}=(13) 1.23=$ $2.23 N_{e} ; N_{e}=7.17$ and $N_{s}=5.82$. Therefore, the feed tray is located at 7.17 stages from top.

\section{Conclusions}

As described previously, dew point can be evaluated after selecting a component to be the reference component, which in the present case was hexane and assuming an initial value of temperature and the values for relative volatility are determined at the corresponding $K$ values for the selected temperature. Then, the value of $K$ for the reference compound is determined after evaluating $K=1 / \sum \alpha_{i} x_{I}$. The calculated value of temperature is compared to the assumed temperature value. Multicomponent distillation problems can be solved manually by means of tray-by-tray calculations of heat and material balances and vapor-liquid equilibrium. Alternative methods have been described widely in literature and are showed in the present paper. Data obtained using these methods provide data that can be used in iterative methods for numerical analysis. The design of equipment has been complemented with formulations that include theory of binary mass transfer and applied to multicomponent systems in matrix forms. This has also been included in computational algorithms taking into account simultaneous heat transfer effects. These advanced models have been incorporated to design software for mass and heat transfer process like distillation, absorption, extraction, and condensation.

This work was supported by the Ministry of Education, Youth and Sports of the Czech Republic within the National Sustainability Programme project No. LO1303 (MSMT7778/2014), the European Regional Development Fund under the project CEBIA-Tech No. CZ.1.05/2.1.00/03.0089 and also by the internal project No. RVO/CEBIA/2019/003 "Vývoj recyklačních a zpracovatelských technologií".

\section{References}

1. R. H. Perry, Perry's chemical engineers' handbook, (McGraw-Hill, 1997)

2. J. D. Seader and E. J. Henley, Separation process principles. (Wiley, 1998)

3. J. R. Couper, Chemical process equipment selection and design. (Elsevier, 2005)

4. J. M. Coulson, J. R. Backhurst, J. H. Harker, J.F. Richardson, Coulson and Richardson's Chemical engineering. Vol. 1, Fluid flow, heat transfer and mass transfer, (Butterworth-Heinemann, 1999)

5. M. S. Ray and D. W. Johnston, Chemical engineering design project: a case study approach. (Gordon and Breach Science Publishers, 1998)

6. R. Taylor and R. Krishna, Multicomponent mass transfer, (Wiley, 1993)

7. M. L. McWilliams, Chem. Eng., 80, 25, 138, (1973)

8. C. J. Geankoplis, Transport processes and unit operations, (Prentice Hall, 1993)

9. R. E. Treybal, Mass-transfer operations. (McGrawHill, 1980) 